Article

\title{
Cyclic Testing for Structural Detail Improvement of CFT Column-Foundation Connections
}

\section{Hee-Ju Kim ${ }^{1}$, Jong-Wan Hu ${ }^{2,3}$ and Won-Sup Hwang ${ }^{1, *}$}

1 Department of Civil Engineering, Inha University, Incheon 402-751, Korea; E-Mail:koyohj@nate.com

2 Department of Civil and Environmental Engineering, College of Urban Science, Incheon National University, Incheon 406-840, Korea; E-Mail: jongp24@incheon.ac.kr

3 Incheon Disaster Prevention Research Center, Incheon National University, 12-1 Songdo-dong, Incheon 406-840, Korea

* Author to whom correspondence should be addressed; E-Mail: hws@inha.ac.kr; Tel.: +82-32-860-7570; Fax: +82-32-873-7560.

Academic Editor: Marc A. Rosen

Received: 7 October 2014 / Accepted: 22 April 2015 / Published: 29 April 2015

\begin{abstract}
In this study, concrete-filled tube (CFT) column-to-foundation connections were investigated experimentally to improve the design of their structural details. Initially, five different types of foundation connections, which were classified according to the design parameters incorporating the types of anchor bolts, shear connectors, base members, and reinforced bars used, were fabricated. After conducting structural experiments on these foundation models, the performance and capacity of the individual model cases from the test results were compared with each other. The test results showed that some of the test models designed according to current design guidelines had problems related to the structural details. Therefore, this study proposed an adequate design methodology to improve the performance of foundation components, such as high tension bolt, base frame members, and embedded plate. An analytical investigation of the force-deformation relationship as well as the characteristic strains distributed over the individual foundation components was performed.
\end{abstract}

Keywords: concrete-filled tube (CFT); base plate; anchor bolts; design parameters 


\section{Introduction}

Design and construction methods have been improved by the development of new construction technologies in the field. In particular, road bridges, as a representative civil engineering structure, have become longer because of the demand for more space, and are constructed using a range of design methodologies. Currently, bridge piers need to be designed with sufficient strength to support the superstructure of such long-span bridges. Moreover, many piers upholding the road bridge have been constructed on space-intensive downtown area. For these reasons, most bridge piers have recently been designed with various types of concrete-filled tube (CFT) columns, which have structural advantages with regard to durability, strength and sustainability. In addition, concrete foundations, as the substructure of a bridge that transfers the loads from the pier to the ground, should be erected using reasonable design and construction methods to secure superior capacity and stable performance.

For such a substructure, bridge piers can be connected to the base foundations using high strength anchor bolts. The anchor bolts installed between the lower pier and concrete foundation help ameliorate the stiffness of the substructure. Furthermore, double base plates are embedded into the concrete foundation and fastened to the anchor bolts under the pier in an effort to improve the behavioral performance and strength capacity. On the other hand, this erection method traditionally used for constructing the foundation connection includes some critical drawbacks associated with the complicated design, overestimated size demand, and unexpected brittle failure. With the increasing dead and live loads transferred from the superstructure, a relatively larger sized concrete foundation is needed for practical construction compared to other system designs. Therefore, there is demand for more anchor bolt installations arranged in 2 or 3 rows. In addition, complicated design details are necessary to accommodate this bolt arrangement with more equipped- and uneconomically larger sized base components as discussed elsewhere [1,2]. This paper proposes new structural details for column-to-foundation connection design to overcome these problems.

Previous studies focused mainly on the I-shape and rectangular CFT column-to-foundation connections for building structures rather than on the circular CFT column ones for bridge structures as discussed elsewhere [3-6]. For example, Lee et al. numerically studied the exposed column-base plate connections about weak axis [4,5] and Astaneh et al. suggested optimum yield conditions after conducting experimental tests with axial and lateral load [7]. In addition to these column-to-foundation connections for building structures, studies about structural details of bridge piers improving seismic performance were mostly conducted.

In particular, pilot studies for the experimental tests (or numerical analyses) conducted on circular CFT column-to-foundation connections are far from sufficient to induce adequate structural details for their practical design. Park et al. [8] proposed new connection details for circular steel piers after performing experimental tests and numerical analyses. They suggested a new pier connection that was replaced with reinforced steel bars acting as the fastened anchors, and examined its behavioral characteristics through reinforcement measures. Finite element (FE) models were designed based on the new structural details presented. After FE analysis, the analysis results were compared with the experimental test results to determine the adequacy of the design methods. The reinforcing bars were found to be adequate to set up the structure with a relatively smaller moment. 
On the other hand, it is difficult to obtain more strength in the case of installing these bars at the foundation anchor of a long span bridge. Therefore, this study examined the drawbacks concerning the established design methodology for circular CFT column-to-foundation connections and the proposed new structural details to overcome these problems. High tension bolts were used to replace the embedded anchors to improve the capacity of the anchor frame. The advantages of installing high tension bolts can be verified through structural experiments performed on the connection specimens. Finally, a strength evaluation on the column base and foundation connection was conducted by analyzing the experimental test results, and new design guidelines were then suggested in this study.

\section{Experimental Section}

\subsection{Design and Details of Specimens}

The aims of this study were to improve the structural design details for circular CFT column-to-foundation connections, and suggest reasonable design equations. To achieve this research aim, some specimens were designed according to the current design guidelines as discussed elsewhere [1,2,9-11]. Table 1 summarizes the design parameters classified as individual model cases. All models had eight anchor bolts placed around the outside of the CFT column.

Table 1. Parameter classification.

\begin{tabular}{ccc}
\hline Specimens & Parameters & Details \\
\hline M-AF & General Anchor, Anchor Frame & Figure 1a \\
H-NF & High-Tension Bolt, No Anchor Frame & Figure 1b \\
H-ST & High-Tension Bolt, Stud & Figure 1c \\
H-IB & High-Tension Bolt, Inner Deformed Bar & Figure 1d \\
H-IA & High-Tension Bolt, Inner Anchor & Figure 1e \\
\hline
\end{tabular}

The M-AF (Mild Steel Anchor Bolt-Anchor Frame) designed according to the current design code was composed of general anchor blots and anchor frames, as shown in Figure 1a. The anchor bolts were attached directly to the anchor frame embedded in the concrete foundation. The anchor frame can withstand lateral loads until the anchor bolts are pulled out or fail by yielding. On the other hand, complicated design details are needed for this foundation type, which make it difficult to predict the accurate pattern of the response mechanism. Although the embedded anchor frame may solidly clamp the anchor bolts to the foundation without slipping, it clearly increases the size of the concrete foundation. As shown in Figure 1b, the H-NF (High Tension Bolt-No Anchor Frame) model as an alternative foundation type was not designed with the anchor frame to resolve the simple design measures. Instead, general steel anchor bolts were replaced with high-tension strength bolts to compensate for the stiffness to resist lateral loads. The high tension bolts can easily fix a double plate also embedded in the concrete foundation.

The H-ST (High Tension Bolt-Stud) model shown in Figure 1c was similar to the H-NF model except for the installation of the shear studs. The eight shear studs were welded to individual high tension bolts to increase the adhesion force to the attached surface. In addition, the upper and lower nuts were added to the upper base plate to enhance the performance of the high tension bolts on the compressive side. 
The H-IB model shown in Figure 1d was comprised of deformed bars also installed in the inside of the C-FT column as well as component members that were also found in the H-ST model (e.g., high tension bolts and embedded double plates). The sixteen deformed bars installed inside were $1150 \mathrm{~mm}$ in length. Finally, the H-1A model shown in Figure 1e was designed with the inner anchor bolts replacing the deformed bars. The inner anchor bolts were fastened between the embedded double plates using nuts. This model can improve the behavioral capacity in terms of the strength, ductility, and force redistribution.

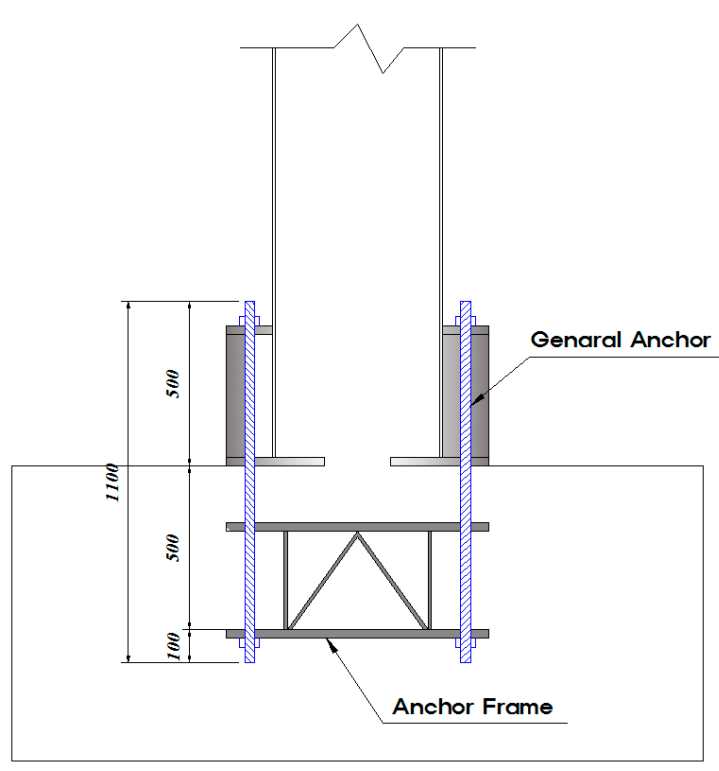

(a)

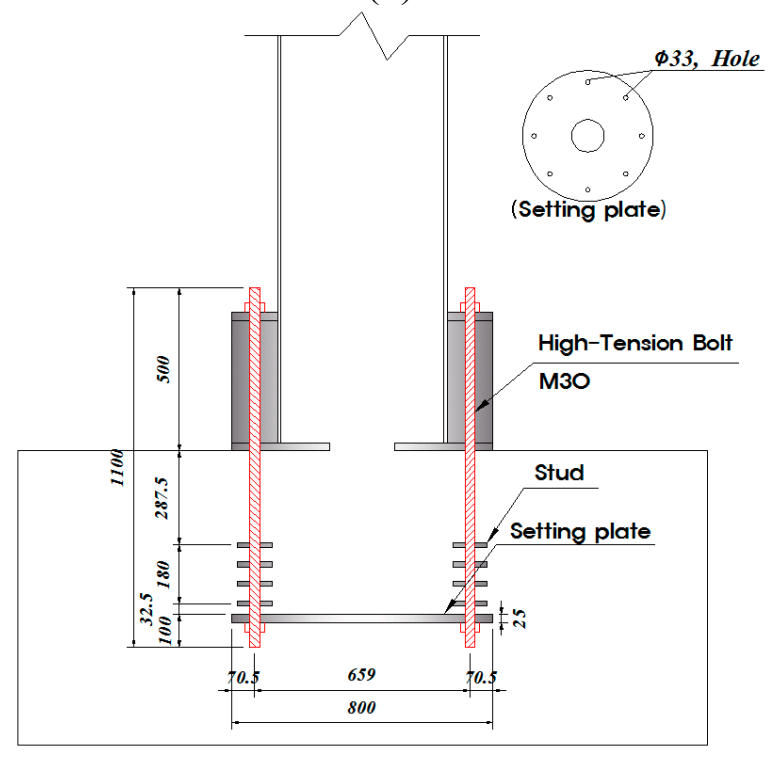

(c)

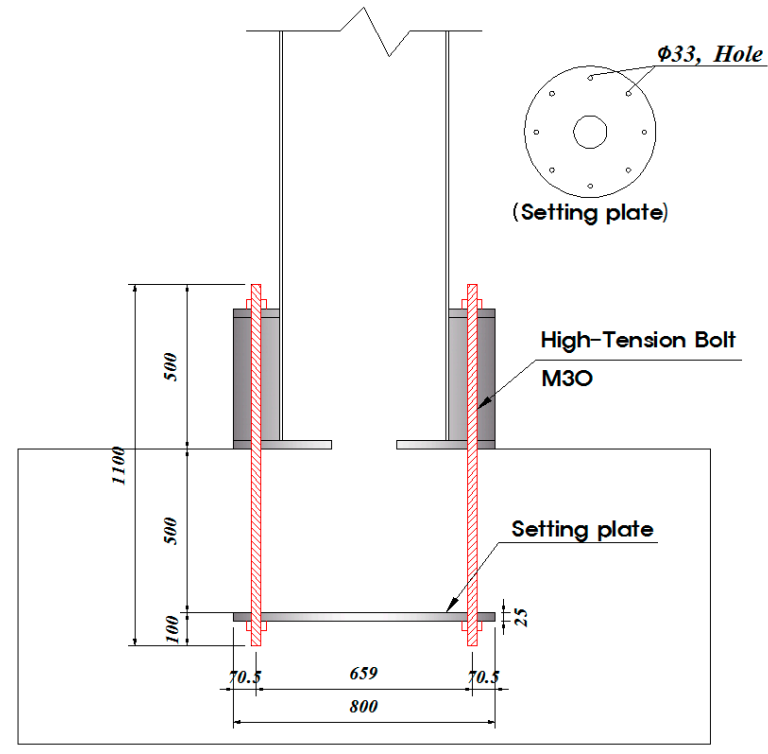

(b)

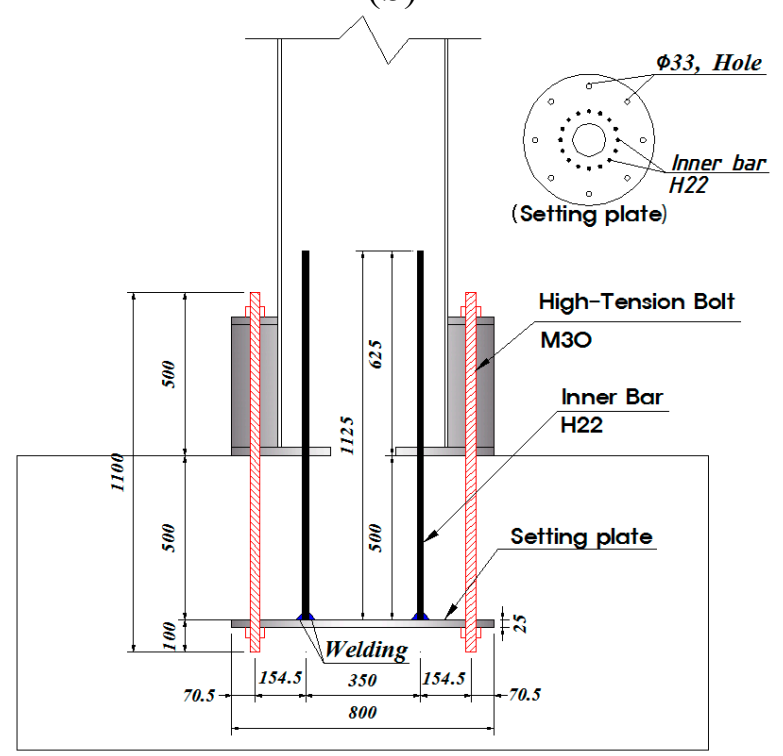

(d)

Figure 1. Cont. 


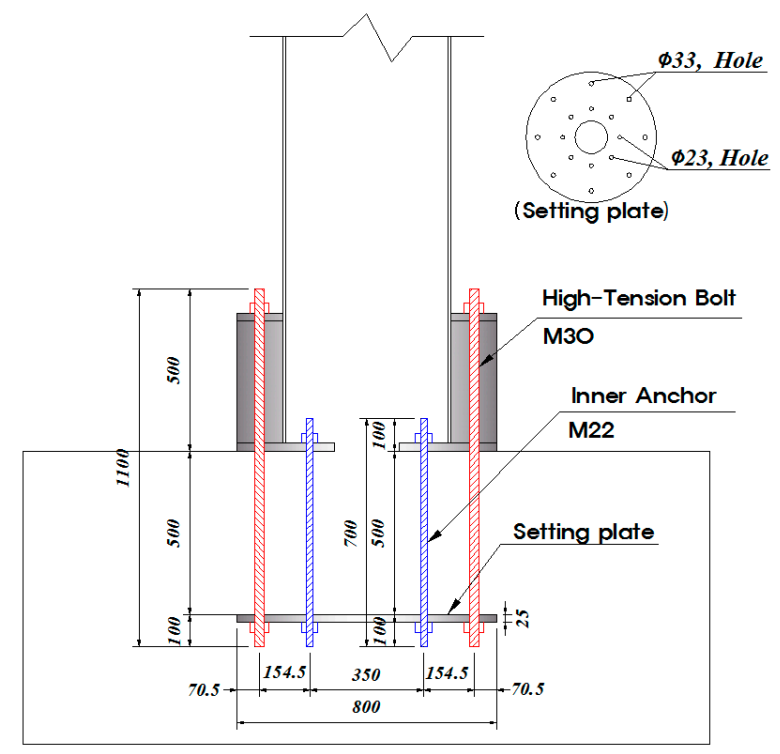

(e)

Figure 1. Parameter classification (a) Mild steel anchor bolt-anchor frame (M-AF) (b) H-NF (c) H-ST (d) H-IB (e) H-IA.

All specimens were fabricated in a full scale, separating column and base parts, and had a $3400 \mathrm{~mm}$ uniform height consisting of a $900 \mathrm{~mm}$ foundation height and a $2500 \mathrm{~mm}$ column height, respectively. The clear distance of the base plates was $375 \mathrm{~mm}$ and the thickness of the ribs was $22 \mathrm{~mm}$. The internal diameter of the column was $500 \mathrm{~mm}$. These member dimensions were applied uniformly to all model cases presented herein. Therefore, the connection details illustrated in Figure 1 result in design parameters that can be used to classify the individual model cases. In addition, Figures 2 and 3 show details of base plates and ribs, and fabrication process, respectively. Table 2 lists the distinctive design details applied to each specimen model.

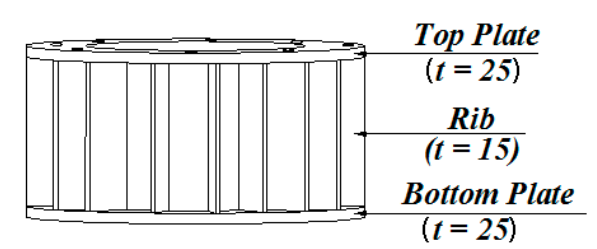

(a)

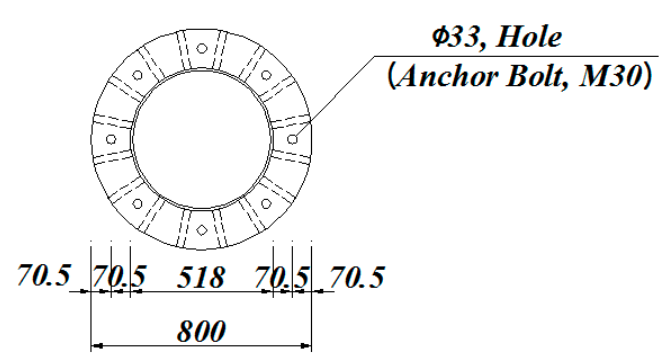

(c)

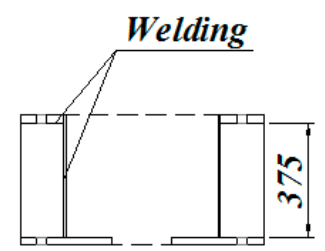

(b)

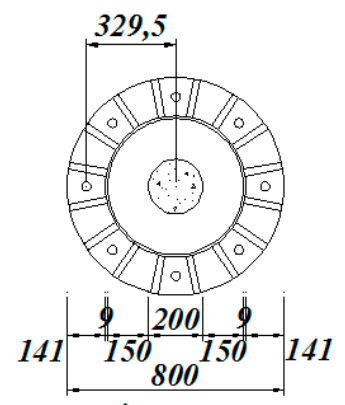

(d)

Figure 2. Details of base plates and ribs (a) base plates and ribs (b) front view (c) sectional view (top plate) (d) sectional view (bottom plate). 


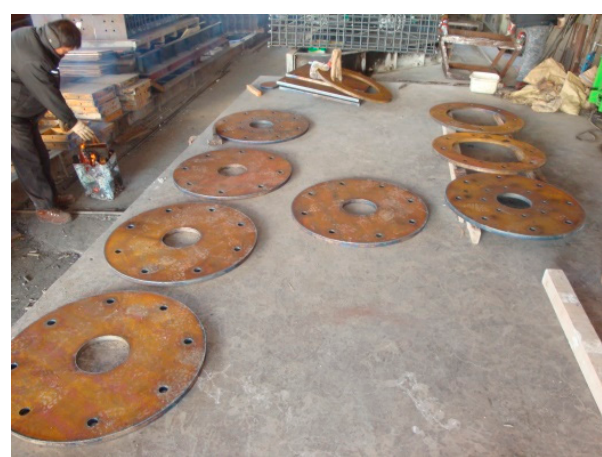

(a)

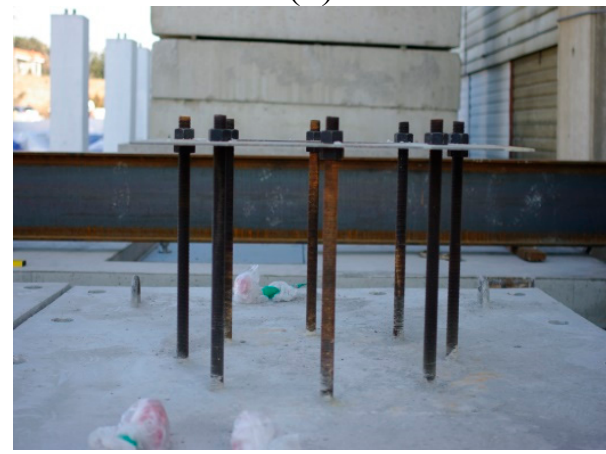

(c)

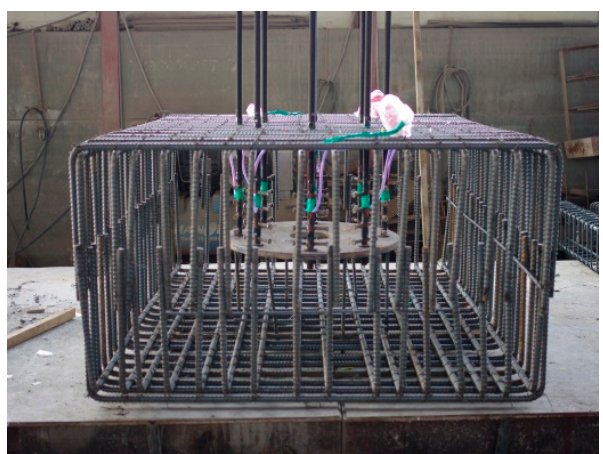

(b)

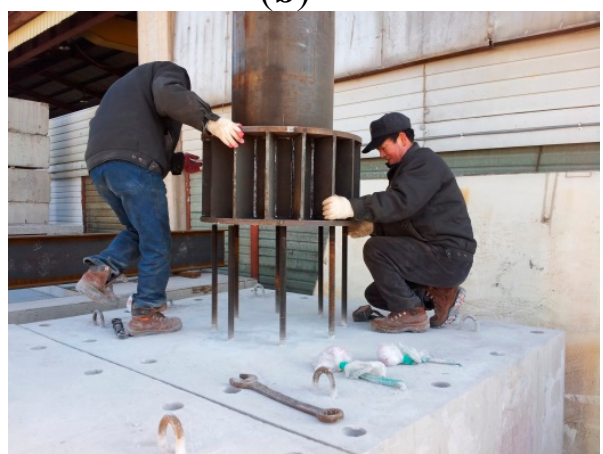

(d)

Figure 3. Fabrication process of specimens (a) Steel tube and base plates (b) Reinforcement placing in foundation (c) Concrete placing in foundation (d) Fabrication of column.

Table 2. Dimensions of the test specimens.

\begin{tabular}{|c|c|c|}
\hline \multicolumn{2}{|c|}{ Classification } & Details (mm) \\
\hline \multirow{3}{*}{ Column } & Height & 2500 \\
\hline & \multirow{2}{*}{ Diameter } & 518 \\
\hline & & 500 \\
\hline \multirow{3}{*}{ Baseplate } & Distance between Baseplates & 375 \\
\hline & Thickness of Baseplates & 25 \\
\hline & Thickness of Ribs & 15 \\
\hline \multirow{3}{*}{ Foundation } & Width & 2210 \\
\hline & Length & 1710 \\
\hline & Height & 900 \\
\hline \multirow{2}{*}{ General and High-tension Anchor Bolt } & Diameter & 30 \\
\hline & Length & 1000 \\
\hline \multirow{2}{*}{ Inner Deformed Bar } & Diameter & 22 \\
\hline & Length & 1125 \\
\hline \multirow{2}{*}{ Inner Anchor } & Diameter & 22 \\
\hline & Length & 700 \\
\hline
\end{tabular}

\subsection{Material Properties}

SM 490, low carbon steel, was used for all specimens. Three tensile coupon tests for each base component member, anchor bolt, and high tension bolt were performed to determine their material properties. Table 3 lists the yield stress, ultimate tensile strength, and elongation ratio obtained from the 
coupon tests. The concrete was pumped into the hollow section tube column and the connected foundation twice. Six cylindrical-shaped concrete pieces were fabricated to measure the average compressive strength. Table 4 lists the concrete compressive strength, which had been pumped primarily and secondarily.

Table 3. Test results of steel.

\begin{tabular}{cccc}
\hline Classification & Yield Strength (MPa) & Tensile Strength (MPa) & Elongation (\%) \\
\hline Steel Pipe & 322.28 & 515.97 & 32.52 \\
General Anchor & 542.92 & 584.05 & 17.03 \\
High-Tension Bolt & 561.91 & 732.68 & 16.25 \\
\hline
\end{tabular}

Table 4. Test results of concrete.

\begin{tabular}{ccc}
\hline Classification & $\begin{array}{c}\text { Average Compressive } \\
\text { Strength (MPa) }\end{array}$ & $\begin{array}{c}\text { Average Compressive Strength/Design } \\
\text { Compressive Strength (\%) }\end{array}$ \\
\hline First & 40.08 & 97.5 \\
Second & 27.36 & 99.0 \\
\hline
\end{tabular}

\subsection{Loading Equipment and History}

The cyclic loads were applied to the specimens using three actuators. As shown in Figure 4, two actuators with a $1000 \mathrm{kN}$ maximum loading capacity were used to reproduce the axial loads while the other with a $2000 \mathrm{kN}$ maximum loading capacity was used to reproduce the lateral loads. The $1500 \mathrm{kN}$ axial load was applied uniformly to take the gravity loads into consideration during the experimental tests, and the increasing lateral loads were imposed steadily by moving the actuator at the end of the CFT column. The displacement control was carried out to reproduce the stable-lateral loads. Figure 5 shows the displacement loading history of the cyclic test. A couple of cycles were performed at each amplitude as discussed elsewhere [6-8,12]. Cyclic tests were carried out until complete failure of the experimental test specimens.

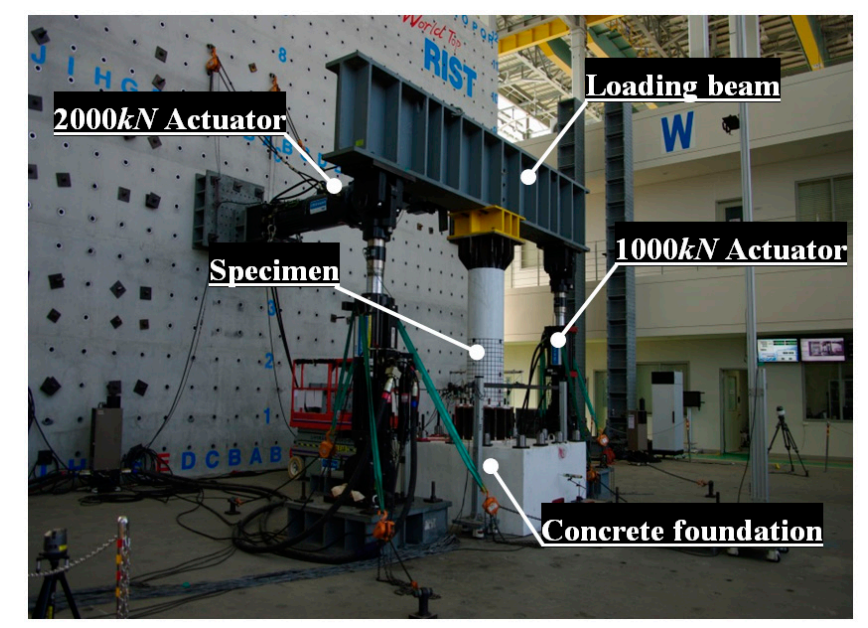

Figure 4. Test setup view. 


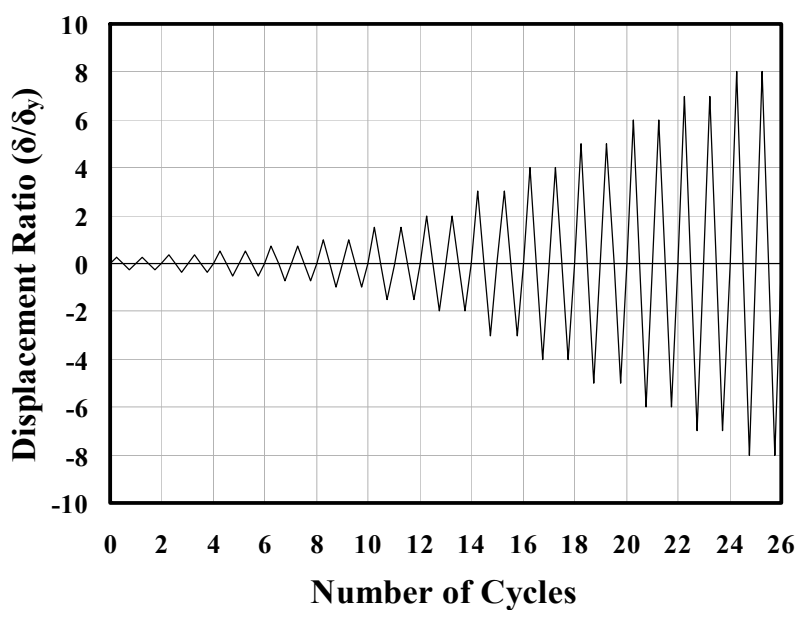

Figure 5. Cyclic loading sequence.

\subsection{Instrumentation}

The experimental data was measured to examine the hysteretic behavior of the individual specimens as discussed by Marson and Bruneau [12]. As shown in Figure 6a, the wire displacement transducer (w-LVDT) was installed on the top of the loading point to measure the lateral displacement. In addition, the displacement transducers (LVDT) were installed to measure the displacements occurring at the half and quarter of the CFT column height.

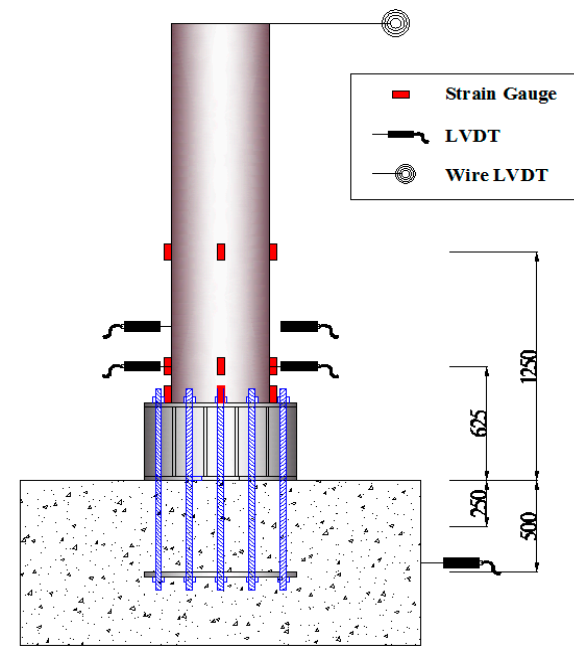

(a)

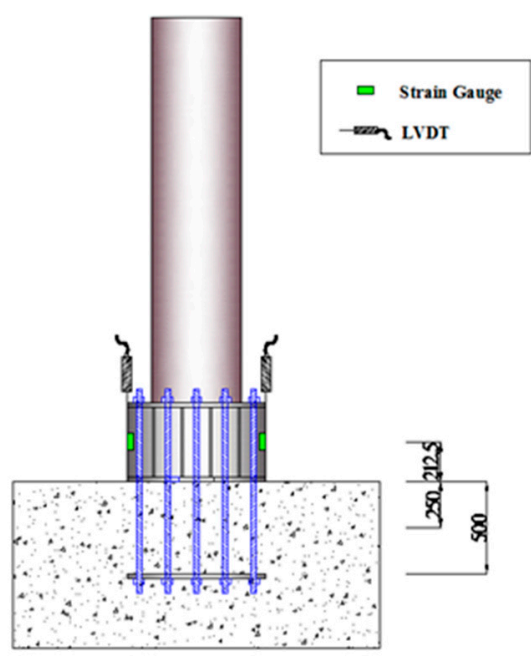

(b)

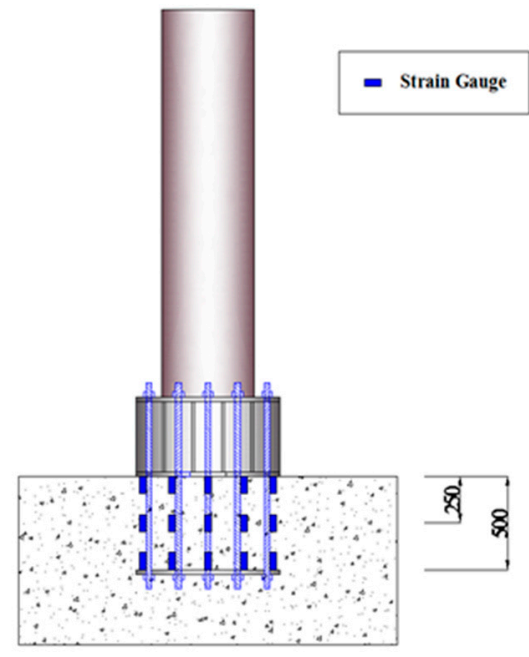

(c)

Figure 6. Locations of instrumentations on specimen (a) Detailed locations of instrumentations on the column (b) Detailed locations of instrumentations on base plates (c) Detailed instrumentations on anchors.

The strain gauges were attached to the bottom of the ribs between both base plates. A total of four gauges were installed on both sides of the ribs on which the load was concentrated mostly when the lateral load was applied. Figure 6a shows the instrumentation for the gauge positions. The strain gauges were attached to different locations for each specimen. In the case of the M-AF and H-IB model, the strain gauges were located on a quarter of the rib, whereas they were located on a half of the rib in case 
of H-NF, the H-ST and H-IA models. In addition, each of the vertical LVDTs was installed symmetrically at both sides of the base plate to measure the lifted displacement of the base plate, as shown in Figure $6 b$.

When analyzing the structural behavior of the column-to-foundation connection, the most important consideration is the anchor. The strain gauges were attached at total three points, the top, middle and bottom, based on the embedded depth to clearly highlight the differences with respect to the materials and inner reinforcement. The instrumentations were installed at the top, middle, and bottom position, which were divided for high-tension and for the inner anchor, and attached to the middle only, which was the same point as the anchor. Figure $6 \mathrm{c}$ shows the location of the strain gauges in the anchor.

\section{Elastic Behavior Characteristics}

To check the behavior characteristics of the anchor in the elastic range, the strain data of each location was compared and analyzed. The strain data according to the embedded depth of the anchor was compared at the maximum elastic range (1.0 $\delta \mathrm{y})$, and the difference in the strain occurrence tendency was confirmed according to the anchor grade. In addition, the changing tendency of the maximum strain, which occurred in the elastic range, was compared according to each location of the strain gauges.

\subsection{Strain Distribution Characteristics of Anchor}

The strain gauges were attached to the same locations of the anchor to analyze the strain distribution characteristics according to the structural details in the elastic range. The embedded depth (Ad) of the anchor was $500 \mathrm{~mm}$, which was the same as the diameter of the column, and each of the strain gauges was installed at the top (A1), middle (A2) and bottom (A3) of the anchor. Therefore, according to the change in the lateral load, the compressive and tensile strain data could be measured. Figure 7 shows the strain distribution characteristics of the anchor according to the embedded depth. The strain distribution characteristics were compared at 1.0 dy $(25 \mathrm{~mm})$, the maximum elastic range. The strain indicated the greatest values below $0.5 \mathrm{Ad}(\mathrm{A} 2)$ in tensile strain. In compressive strain, in addition to the tensile strain, the greatest strain values occurred at the top (A1). The strain was barely measurable at the bottom (A3). At the top, the tensile strain was one and a half times greater than the compressive strain. As the tensile anchor supported the external load, the deformation of the tensile anchor took place, and small strain occurred because the load was not transferred to the compressive anchor, but to the foundation.

Figures 8-10 present the changes in the tendency of the strain according to the drift ratio in the elastic range. The strain installed at the right side of the neutral axis was compared because the strain values were similar based on the right side of the neutral axis was compared because the strain values were similar based on the neutral axis. The strain values of all specimens were similar for the attached locations in the compressive side. On the other hand, the tensile strain of M-AF was relatively higher than that of the other specimens at the top and middle except for the bottom, and the strain occurrence tendency was similar for the other specimens with the high-tension bolt installed. These results were attributed to the anchor grade and not to the differences in the structural details. Therefore, the strain values of the general anchor were greater than those of the high-tension bolt. 


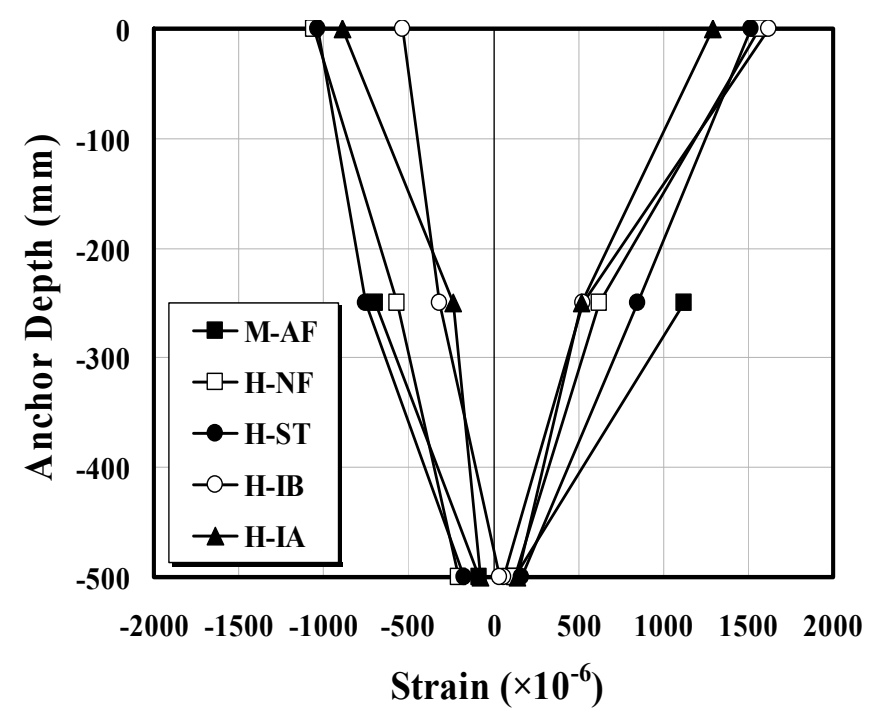

Figure 7. Strain distribution of the embedded length.

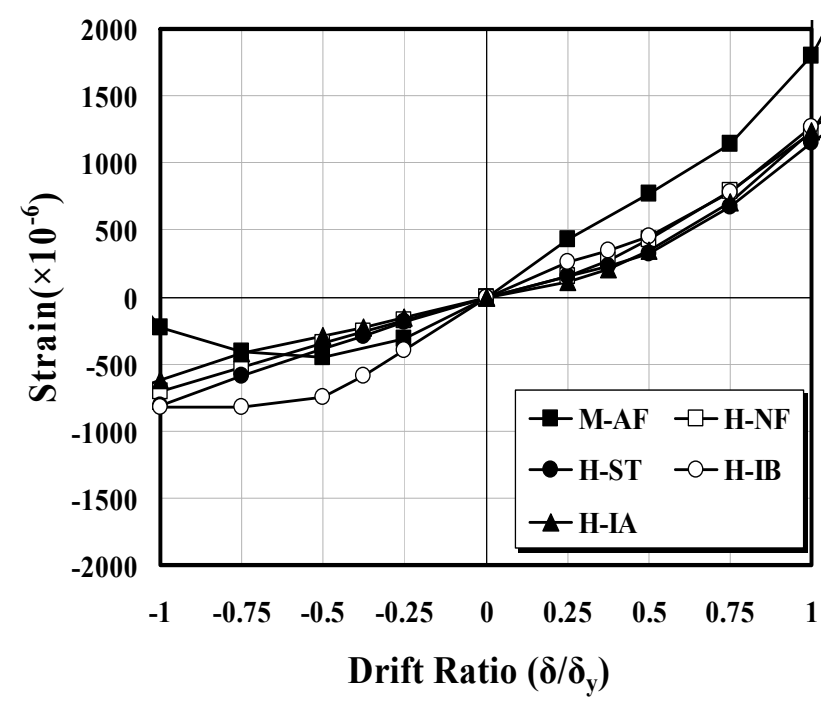

Figure 8. Load-strain relation of the anchor in the elastic range $\left(A_{1}\right)$.

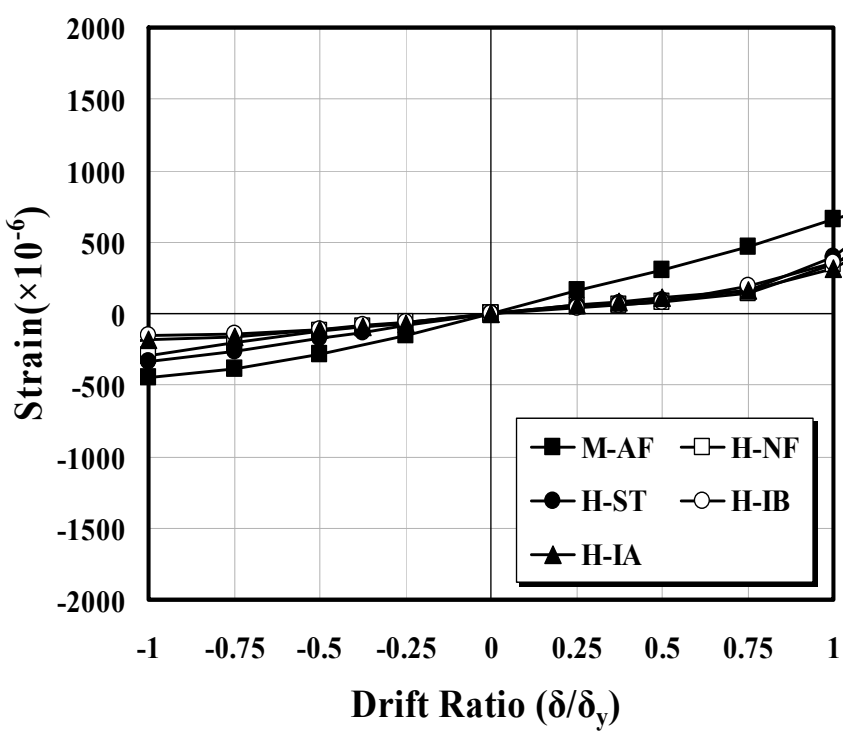

Figure 9. Load-strain relation of the anchor in the elastic range $\left(A_{2}\right)$. 


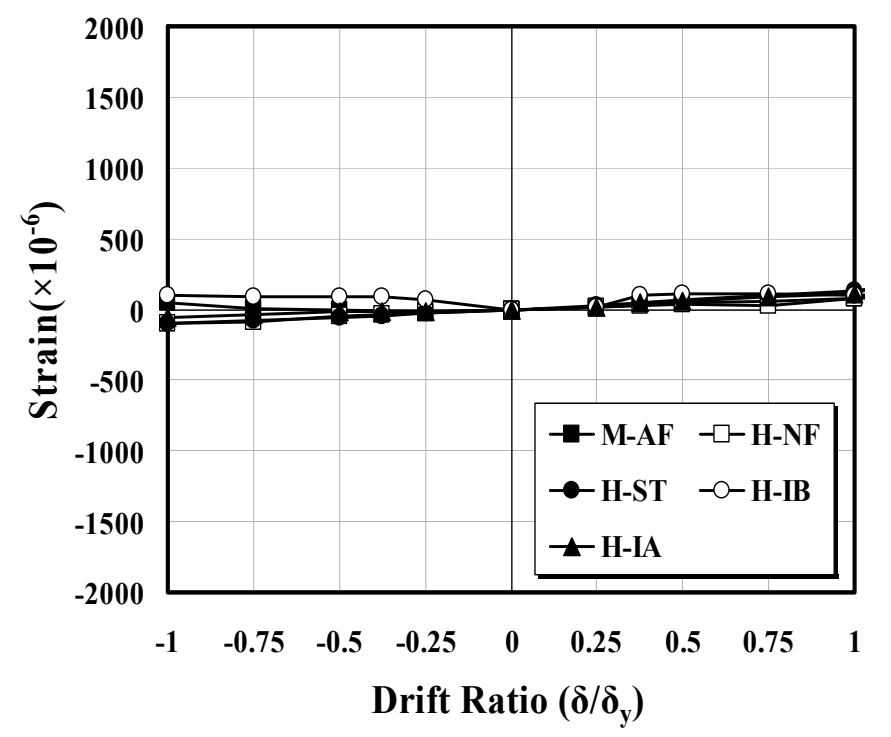

Figure 10. Load-strain relation of the anchor in the elastic range $\left(\mathrm{A}_{3}\right)$.

\subsection{Strain Distribution Characteristics of the Base Plate}

The load-strain relations of the rib were examined to check the strain distribution characteristics of the base plate, as shown in Figure 11. The strain values of the rib showed an opposite trend unlike the anchor according to the load directions. Therefore, in case where the rib was located on the tensile side, the strain values were barely measurable because the load was not transferred by the lift of the base plate. On the other hand, because the compressive load was transferred to the rib, which supports the base plate on the compressive side, the compressive strain became great by the increase in load.

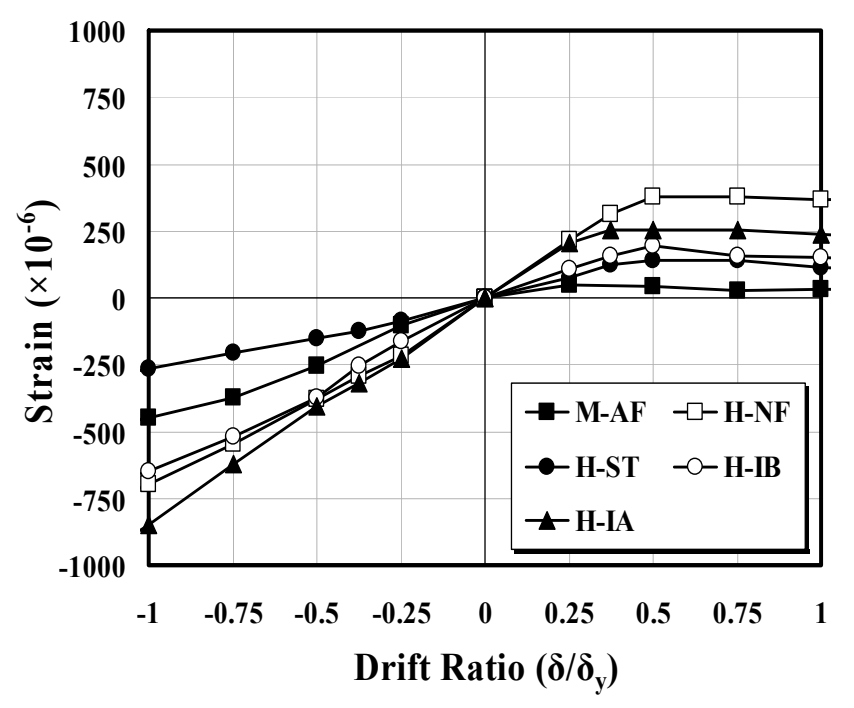

Figure 11. Load-strain relation of the base plate in the elastic range.

The tensile strain rarely appeared for all specimens and the compressive strain was increased linearly (Figure 11). In particular, the compressive strain of H-ST was relatively smaller than that of the other specimens. The strain of the rib was not measured because the compressive load was transferred directly to the anchor by the nut, which was also installed on the upper base plate and not by the effect of the stud on the bottom of the anchor. 


\subsection{Strain Distribution Characteristics of Column}

When the column moved from the tensile to compressive direction or from the compressive to tensile direction by introducing a lateral load, tensile and compressive strain of the column occurred and the values were more relatively greater at the bottom of the column. Figure 12 shows the maximum strain distribution characteristics according to the location of the installed strain gauges, and the strain values were compared in the maximum elastic range, $1.0 \delta \mathrm{y}(25 \mathrm{~mm})$. In the elastic range, it was recognized that the strain values were highest at the bottom (C3) of the column. On the other hand, the differences in the strain values were not great, and strain was similar for each location because the strain in the elastic range was early behavior of the actuator introducing the load,

Figures 13-15 show the changes in the strain according to the load for the attached locations. Figures 14 and 15 show the strain of the quarter and bottom points. The changes in strain for all specimens were similar in the elastic range. On the other hand, Figure 14 shows the strain at the half of the column, and the tensile and compressive strain values of H-IA were relatively higher than those of the other specimens. The strain was attributed to the enhanced bond between the column and the foundation due to the inner anchor installed to improve the applicability of the high-tension bolt.

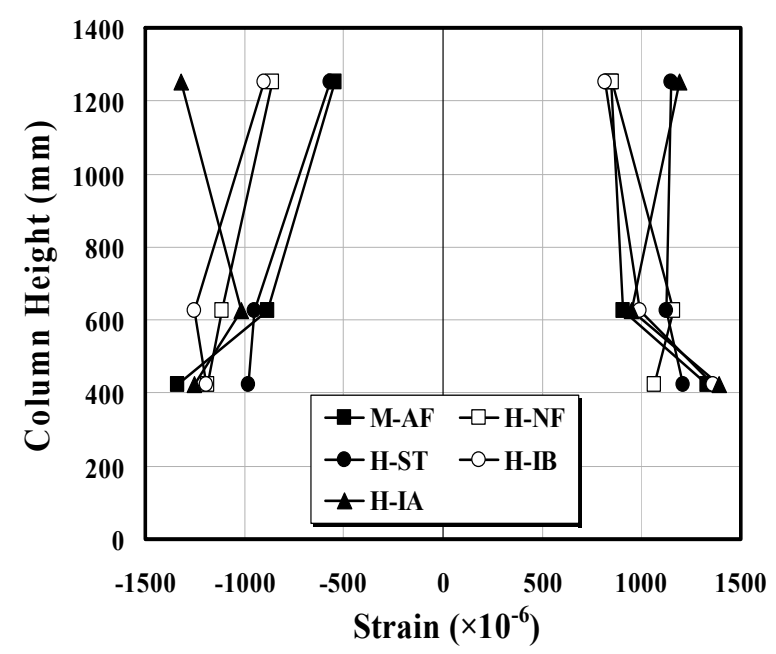

Figure 12. Strain distribution for the column's height.

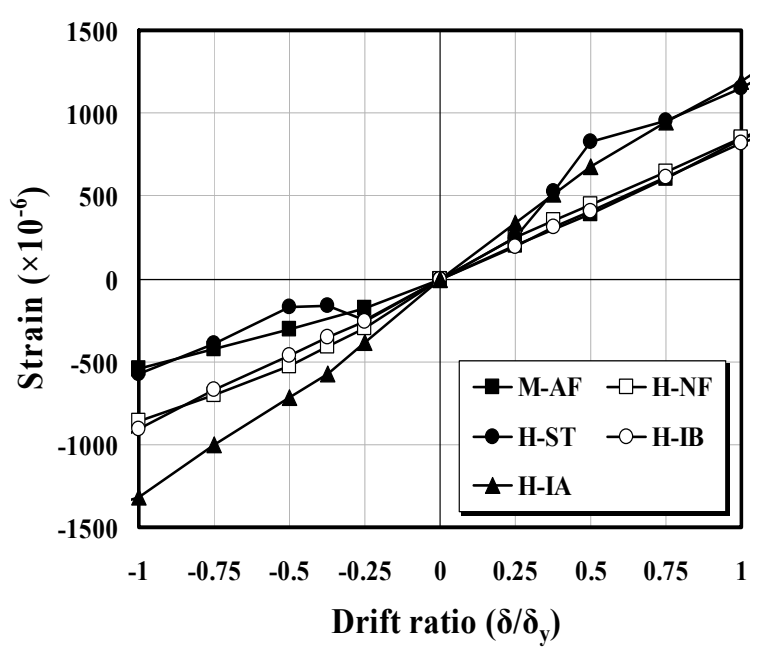

Figure 13. Load-strain relation of the column in the elastic range $\left(\mathrm{C}_{1}\right)$. 


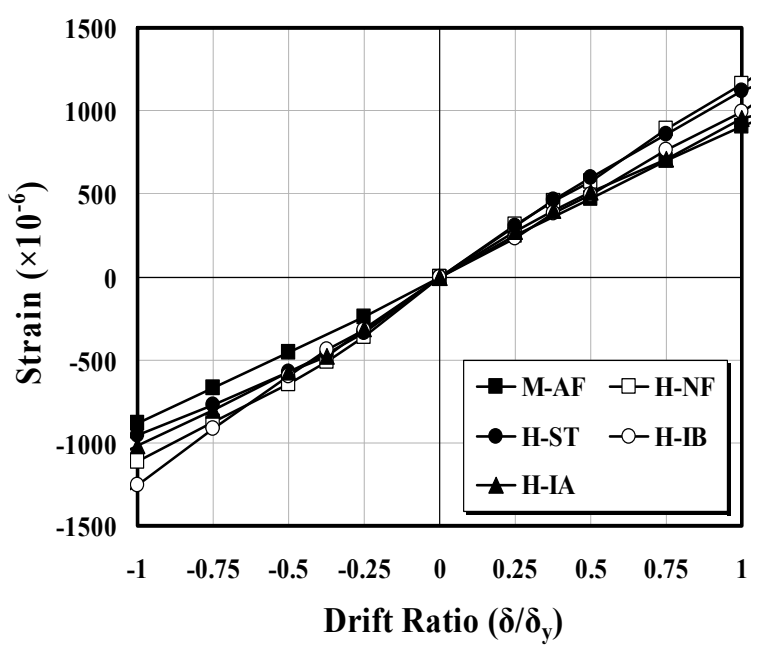

Figure 14. Load-strain relation of the column in the elastic range $\left(\mathrm{C}_{2}\right)$.

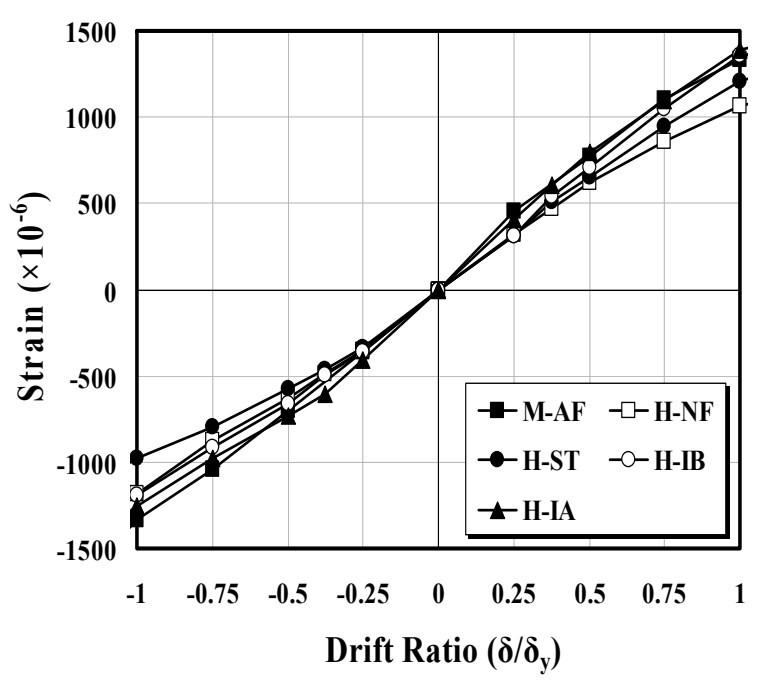

Figure 15. Load-strain relation of the column in the elastic range $\left(\mathrm{C}_{3}\right)$.

\section{Hysteresis Curve under Cyclic Loading}

\subsection{Comparison of Deformed Capacity}

The behavior on each detail was confirmed from w-LVDT at the top of the specimens. Figure 16 shows the load-displacement relationship of M-AF. The displacement decreased linearly when the load was applied. Unlike M-AF, H-NF had a high-tension bolt installed instead of the general anchor, and Figure 17 shows the load-displacement relationship. The displacement decreased gradually when the load was applied and the displacement decreased sharply after the load.

Local bucking for H-NF occurred at the column because the yield and ultimate strength of H-NF was increased more than M-AF. In addition, the tensile failure for M-AF occurred by the increased deformation of the anchor. The failure was attributed to differences in the anchor grade. The tendencies of the load-displacement curve and the failure types differed according to the anchor grade.

Figure 18 shows the load-displacement hysteresis curve of H-ST. A high-tension bolt was installed, and the effect of the stud and added nut was checked. The early strength was similar to that shown in Figure 17 because the same anchor grade was used. The stud installed in the foundation did not influence 
the early behavior. On the other hand, additional research on the location of the installation is needed because the stud distributed the compressive stress in the elastic range. The added nut in the base plate influenced the load-displacement curve. Because of the nut supporting the base plate, the compressive load of the column was transferred directly to the high-tension bolt, and the displacement decreased with decreasing load. Therefore, there was no pinching.

Figures 19 and 20 present the load-displacement curves of H-IB and H-IA. For H-IB, the displacement according to the load decreased gradually because the inner deformed bar was installed longitudinally and the behavior was stable. Therefore, buckling at the bottom of the column occurred by the reinforcing deformed bar in the column, and the load-displacement curve was stable, as shown in Figure 19.

Figure 20 presents the load-displacement of H-IA with the inner anchor and the maximum drift ratio, $8 \delta$ y. The same high-tension bolt was installed in H-IA and H-NF but the hysteresis behavior was similar to H-IB because of the reinforcing method. The sharp decrease in displacement with only a high-tension bolt could be changed to stable behavior by a reinforcing method. In addition, because of the inner anchor, H-IA was more advantageous in the deformation capacity than $\mathrm{H}$-IB and the pinching effect was reduced considerably.

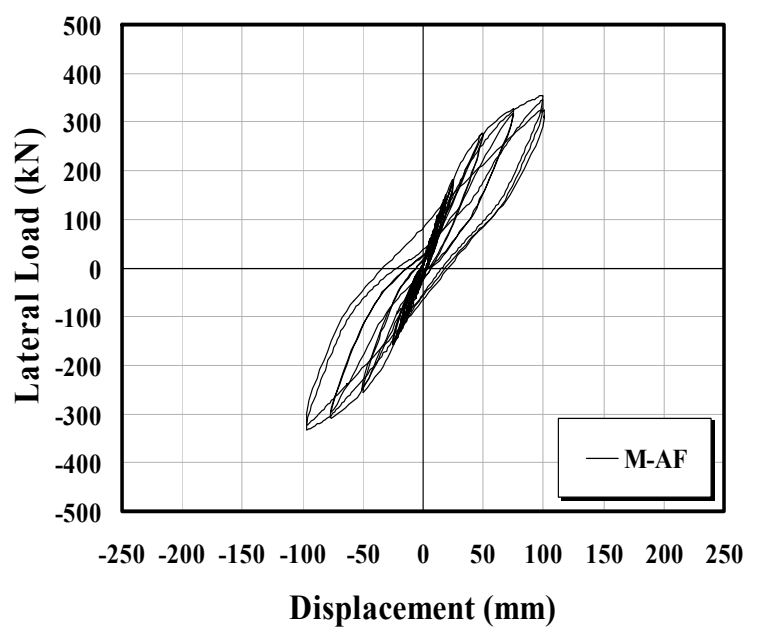

Figure 16. Hysteresis curve of M-AF.

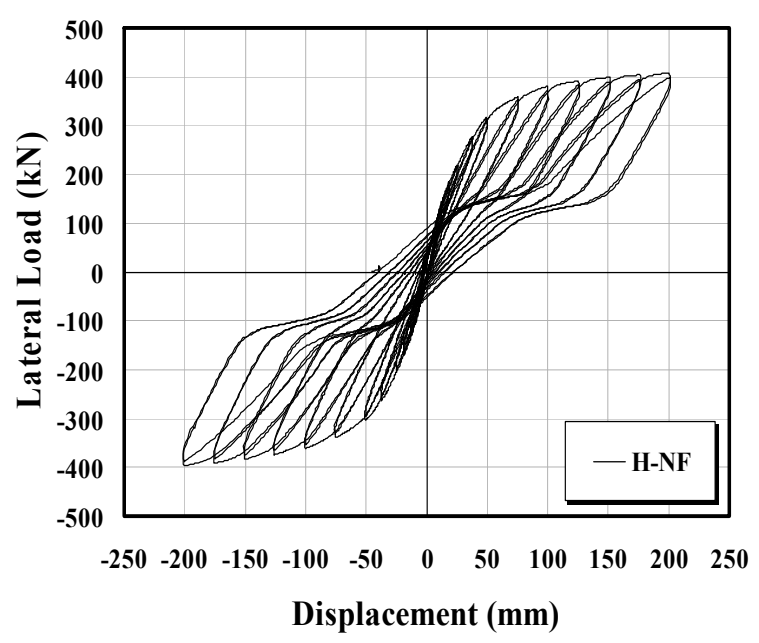

Figure 17. Hysteresis curve of H-NF. 


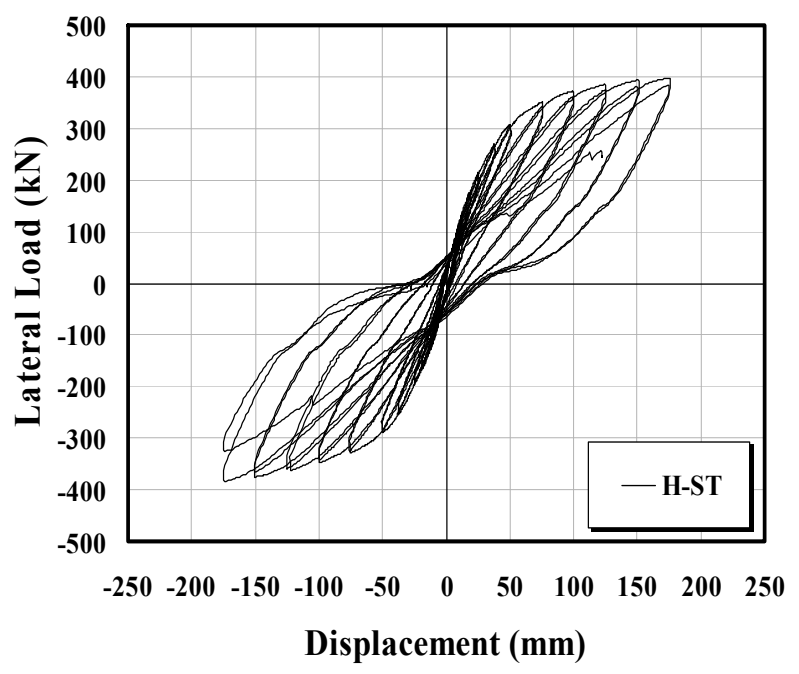

Figure 18. Hysteresis curve of H-ST.

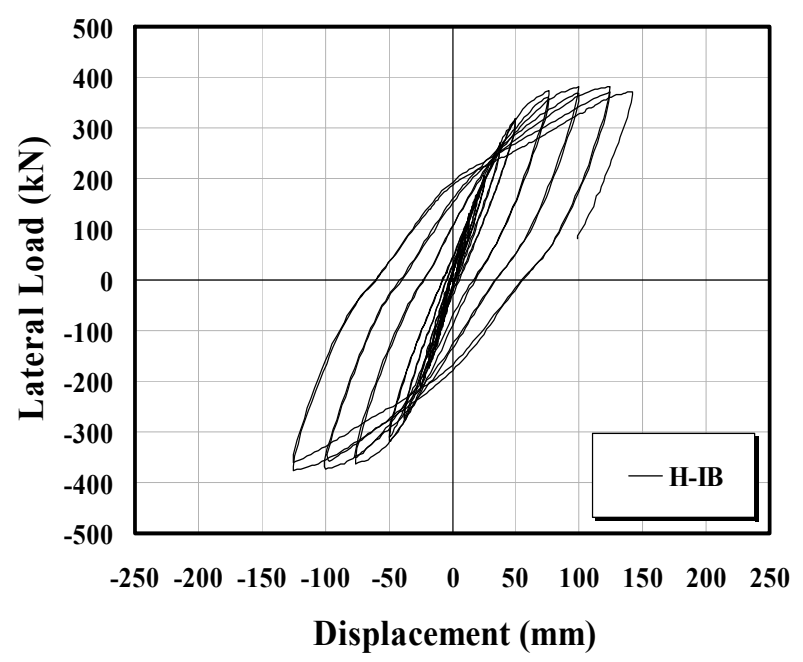

Figure 19. Hysteresis curve of H-IB.

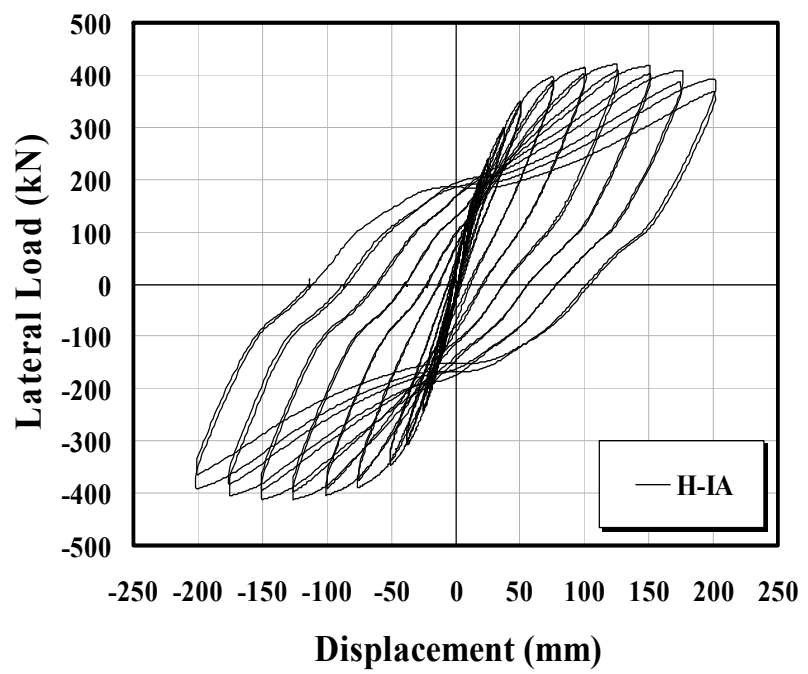

Figure 20. Hysteresis curve of H-IA. 
Therefore, the hysteresis behavior according to the reinforcing method was different but the reinforced specimens, $\mathrm{H}-\mathrm{IB}$ and $\mathrm{H}-\mathrm{IA}$, were more stable than $\mathrm{H}-\mathrm{NF}$ without reinforcement. Accordingly, it is believed that the high-tension bolt is more advantageous in the strength side than the general anchor.

\subsection{Comparison of Strength Characteristic}

Figure 21 shows the load-displacement envelope curves. Failure of the connection for M-AF and the buckling failure of the connection by the nut for H-ST occurred, and the strength increased gradually and the envelope curve reached the maximum load after yield. Buckling occurred at the bottom of the column for H-NF but the tendency of the envelope curve was similar to the other two specimens, M-AF and H-ST, because buckling occurred when the load reached the maximum. For H-IB and H-IA, which were reinforced, the strength decreased slowly after the ultimate load. The load decreased gradually after the ultimate load because buckling occurred after yield at the bottom of the column.

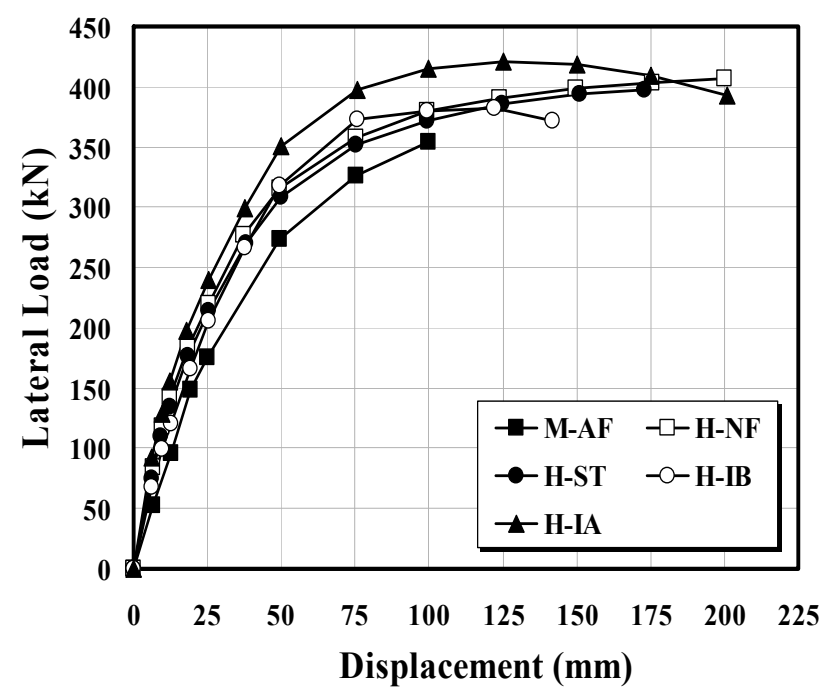

Figure 21. Load-displacement envelope curves.

The differences in the deformation capacity were confirmed according to the anchor grade, even though the load-displacement curves and the accumulated dissipated energy were selected to clearly analyze the differences. Generally, to evaluate the damage to the structure, the absorbing and dissipated capacity until failure is an important factor to estimate the structure. In particular, the stability of the structures can be examined by calculating the real absorbing and dissipated capacity from the external load and the comparison of total energy. This can be defined as the inner area of the load-displacement hysteretic curves.

The load-displacement hysteretic curves differed according to the structural details but the accumulated dissipated energy curves were not different by $3 \delta$ as shown in Figure 22. For H-NF, the amount of the early energy absorption was similar but there were large differences after $3 \delta y \sim 4 \delta y$, where the buckling occurred at the bottom of the column. Large differences were found in the deformation capacity because the anchor grade influenced the failure of the structure. The installation of a hightension bolt decreased the energy absorption in the deformation capacity compared to the general anchor. 
In the strength side, however, the energy absorption was verified in terms of the various structural details because the installation of the high-tension bolt is more advantageous.

For H-ST, the early accumulated dissipated energy was similar to the H-NF because the same anchor grade was used. On the other hand, the accumulated dissipated energy of H-ST was different from $\mathrm{H}$ NF after $3 \delta y$. The tendency of the load-displacement hysteretic curve is believed to have changed because of the added nut on the base plate. These differences occurred because the added nut prevented deformation and distributed the compressive load to the anchor and foundation. Therefore, the nut had a greater effect on the deformation capacity than the stud, and it was believed that H-ST was more advantageous than H-NF with only a high-tension bolt in the energy absorption.

The energy capacity of the reinforced specimens, H-IB and H-IA, was the same as that of the other specimens with a high-tension bolt until $2 \delta \mathrm{y}$. After $2 \delta \mathrm{y}$, the tendencies of the energy capacity clearly differed according to the reinforcing method. The final load and displacement of H-IA were the greatest, and in each step, the H-IB's displacement and load showed an increase in energy capacity. Replacing the general anchor to the high-tension bolt maintained and improved the performance of the structure and the reinforced types were more advantageous than H-NF. Therefore, to remove the anchor frame and improve the performance of the structure instead of replacing the high-tension bolt, installing an inner deformed bar and inner anchor as reinforcement, are more advantageous than the installing a stud.

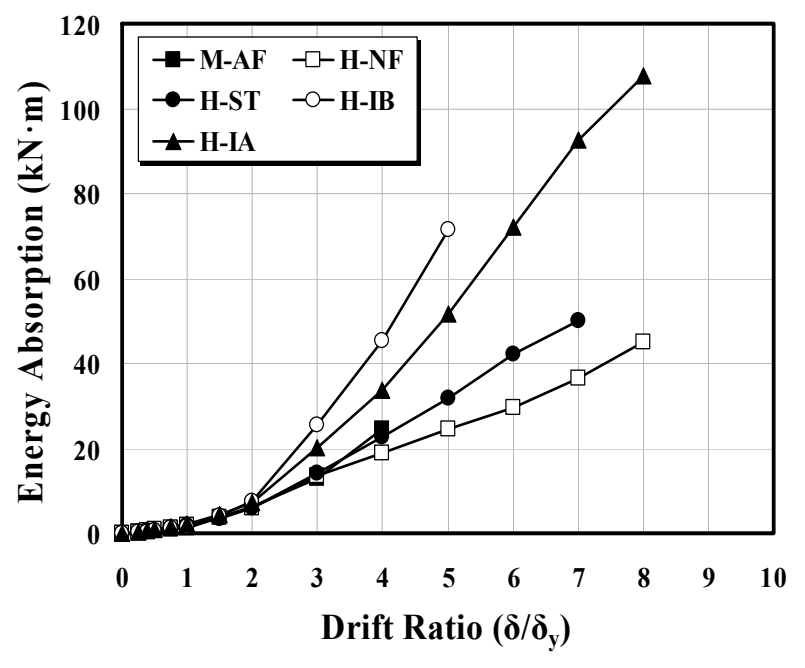

Figure 22. Accumulated dissipated energy curves.

\section{Failure Types}

\subsection{Failure of the Connection}

The behavior characteristics of the structures could be predicted using high levels of instrumentation on the specimens. Through these predictions, the final failure types of the structures could be confirmed according to the anchor grade, and the final failure type of M-AF was found to be the failure of the connection by tension.

M-AF was made from the general anchor, which was used in the current construction, and the anchor frame was installed in the concrete foundation. Pullout of the anchor occurred in the early loading, as shown in Figure 23a. The 3 anchors were pulled out according to the load direction because 
the lateral load caused a lift in the base plate and the pullout length of the outermost anchor was the longest. Therefore, the difference in the load-displacement hysteresis curve occurred when the same load was applied twice.

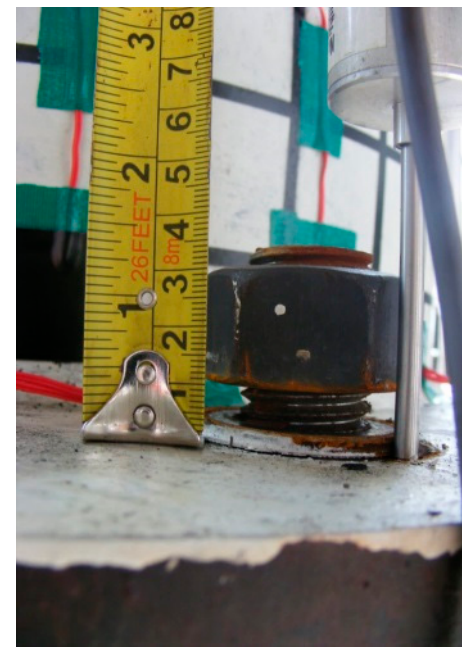

(a)

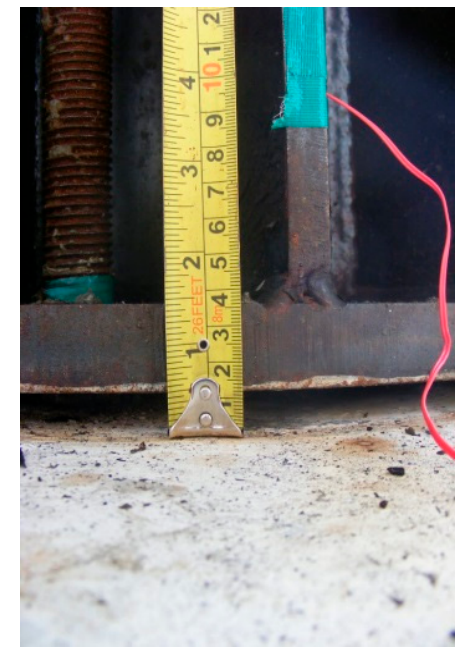

(b)

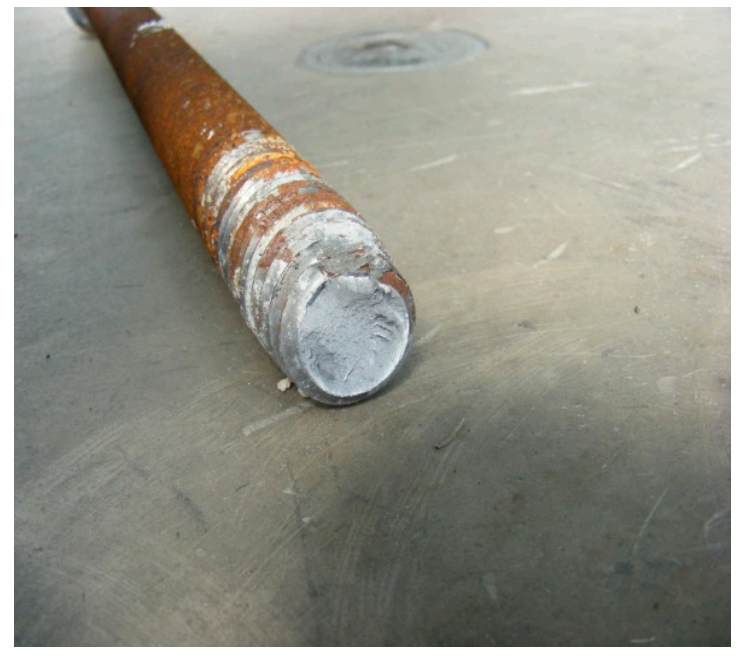

(c)

Figure 23. Detailed failure shapes of M-AF (a) Pullout of anchor (b) Lift of base plate (c) Tensile failure of the general anchor.

Figure $23 \mathrm{~b}$ shows the lift in the base plate according to the increase in lateral load. Because the lifted displacement of the opposite base plate occurred when a lateral load was pulled, the pullout of the anchor was accelerated. Subsequently, failure took place when the lateral load reached the failure strength and anchor failure occurred in M-AF. Figure 23c shows the results of the connection failure, and tensile failure occurred when the deformation capacity of the anchor reached the limit by the lift in the base plate.

The final failure type of H-ST was connection failure by buckling of the high-tension bolt located between the base plates. In addition, inelastic buckling at the bottom of the column occurred and Figure 24a shows the final failure. For H-ST, the pullout of the high-tension bolt barely occurred in the elastic range, and it is believed that the added nut under the upper base plate prevented pullout of the high-tension bolt. The crack on the concrete foundation and the lift in the base plate began to develop after that. As shown in Figure 24a, nonlinear buckling of the high-tension bolt was much more developed according to the increase in load because the compressive load was transferred to the high-tension bolt by the added nut. 


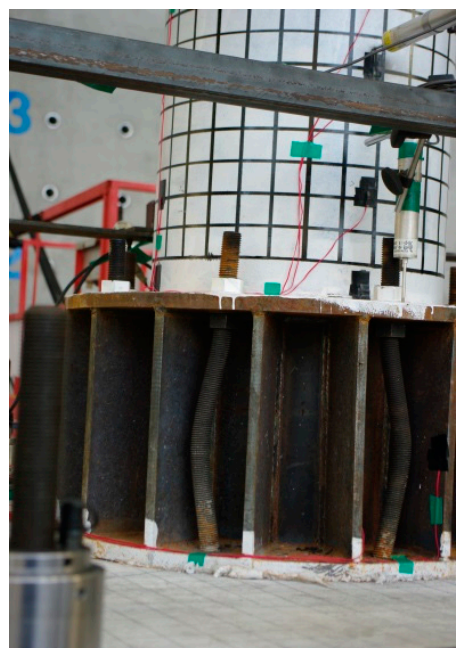

(a)

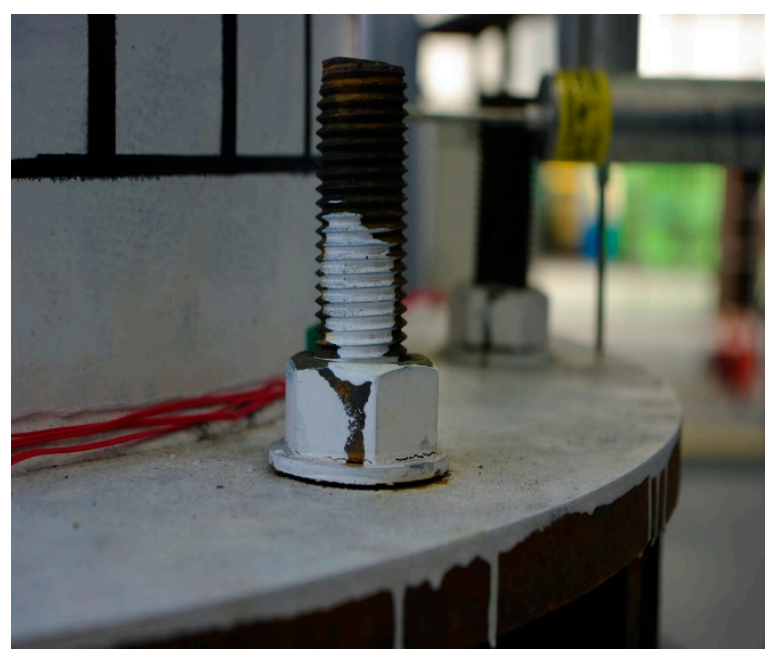

(b)

Figure 24. Detailed failure shapes of H-ST (a) Final failure shape of H-ST (b) Pullout of high-tension bolt.

\subsection{Failure of the Column}

Buckling at the bottom of the column was observed in the 3 specimens. H-NF was simply designed to install the high-tension bolt without an anchor frame unlike the M-AF and the final failure is presented in Figure 25a. Similar to M-AF, the pullout of the high-tension bolt took place in the early elastic range, and the maximum pullout displacement occurred at the outermost bolt. In addition, the lift of the base plate was confirmed and was similar to the early elastic behavior of M-AF. On the other hand, the crack of the concrete foundation was observed in the early elastic range unlike M-AF. In the case of M-AF, the crack of concrete developed after anchor failure. When the load was applied much more, it was confirmed that the small crack developed by deformation of the high-tension bolt. The deformation capacity of the connection for H-NF was improved when the anchor was replaced at the high-tension bolt, and it is then believed that relatively weak column failure took place. Therefore, the final failure of H-NF was buckling at the bottom of the column.

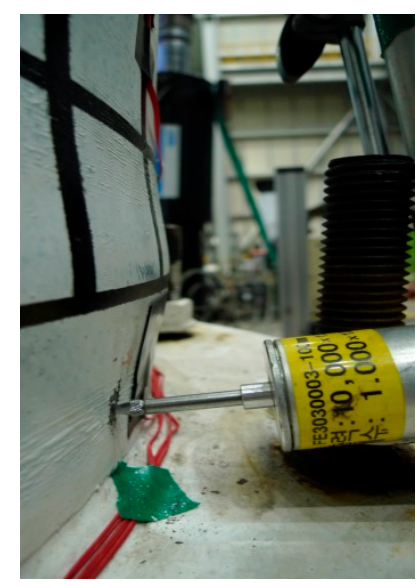

(a)

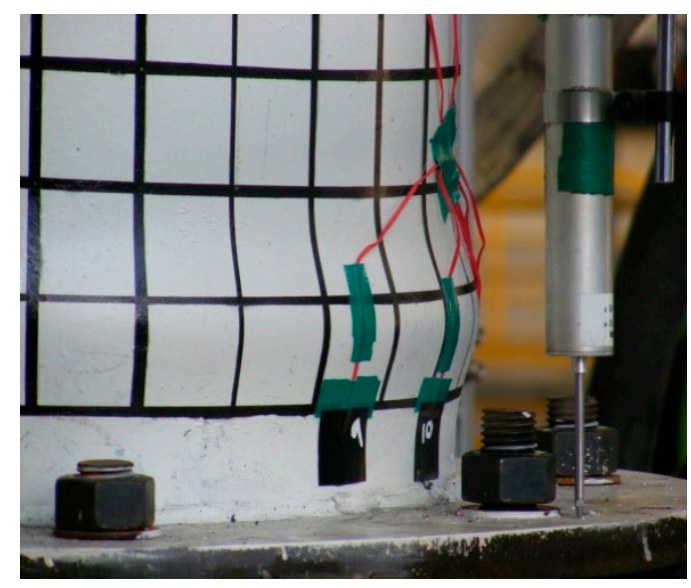

(b)

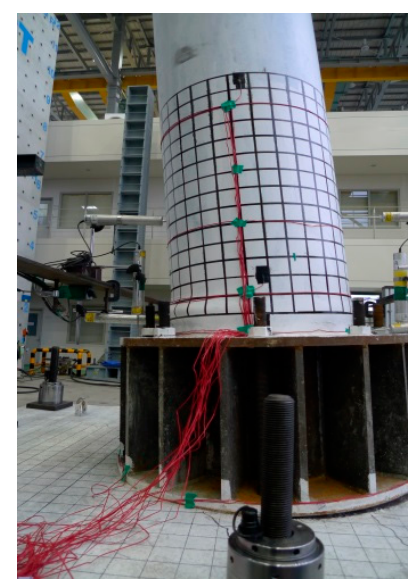

(c)

Figure 25. Failure shape by buckling of the column (a) Failure shape of H-NF (b) Failure shape of H-IB (c) Failure shape of H-IA. 
H-IB was designed to install a deformed bar in the longitudinal direction and the deformed bar was not installed directly on the high-tension bolt but just added from the column to the foundation. In the early loading sequence, the pullout of the high-tension bolt, the small crack and the lift of the base plate, which were observed in all specimens except for H-ST, were observed. Those were more developed while the load was increased. After the early loading sequence, pullout of the high-tension bolt occurred less than the other specimens by the reinforced inner bar. In addition, buckling at the bottom of the column took place because the connection capacity of the foundation and the base plate was improved by the inner deformed bar. Therefore, the final failure was buckling at the bottom of column, as shown in Figure $25 b$.

H-IA was designed to install as many inner anchors as high-tension bolts and the connection capacity was improved like H-IB. The pullout of the high-tension bolt barely occurred in the early elastic range unlike the other specimens. Pullout of the high-tension bolt was reduced because the reinforced inner anchor was tightened with the nut, which caused a lift in the base plate small. Local buckling appeared slowly at the bottom of the column in the inelastic range between 7 and $8 \delta y$.

These results were attributed to the difference in the reinforcement method. That is, significantly more deformation of the column occurred by tightening the base plate with the inner anchor for H-IA because the inner deformed bar was just added without a direct connection to the nut to strengthen the flexural rigidity of $\mathrm{H}-\mathrm{IB}$.

The final failure of H-IA was the buckling at the bottom of the column, which was the same as H-IB. Because the connection capacity of H-IB and H-IA was improved by the reinforcement, the failure was transferred to the column that was relatively weak. On the other hand, an examination of the behavioral characteristics and the hysteresis behavior of the column and anchor showed that a reinforcing method, such as H-IB and H-IA, is more advantageous to improving the applicability of the high-tension bolt.

\section{Conclusions}

This study focused mainly on new structural details concerning the design methodology for circular CFT column-to-foundation anchor connections. The experimental specimens were designed based on some design parameters, and structural experiments were conducted to suggest reasonable guidelines for connection design. The performance of these foundation connections were analyzed by examining the resulting data obtained from the experimental tests. More conclusions are as follows:

(1) The failure type of each circular CFT column-to-foundation connection can be classified as anchor failure and local buckling at the column base. The specimens with general anchors and anchor frames exhibited tensile anchor failure. On the other hand, the specimens with high tension bolts showed local bucking failure under a load. It was thought that the failure type changed because of strength increment. Therefore, to ensure sufficient strength of the column-to-foundation connections, installing high-tension bolts is reasonable.

(2) The experimental loading tests revealed that the specimens with high tension bolts exhibited better structural performance than those with general anchors or anchor frames. In addition, The H-NF's behavior without anchor frames was similar to M-AF's in lifted displacement and crack of concrete foundation so it was thought that installation of anchor frames little affects structure's 
behavior. For this reason, this study suggested new structural details for design using high tension bolts.

(3) The envelope curves used mostly for estimating the energy dissipation were obtained from the experimental tests. Both curves compared to each other clearly showed their differences according to the failure types, such as the tensile fracture and local buckling. The H-IB and H-IA specimens with inner reinforcing showed more energy dissipation and especially, H-IB had maximum 1.39 times more energy dissipation than H-IA. The H-IA's accumulated dissipated energy for each section, however, was more increased than the H-IB's. Therefore, it is thought that the specimen with inner reinforcing is more advantageous than that with the high-tension bolts.

(4) For the purpose of replacing the established types (i.e., M-AF model), four specimen types newly proposed herein displayed different behavioral characteristic. With the exception of anchor frames, specimens with high tension bolts, which generally show better performance, need to be applied as inner reinforcements to improve the performance of high tension bolts.

\section{Acknowledgments}

This work was supported by INHA UNIVERSITY Research Grant and Development of Base Anchor System Applying High Strength Steel of POSCO E\&C.

\section{Author Contributions}

All authors have contributions for this paper. Hee-ju Kim, Jong Wan $\mathrm{Hu}$, and Won-sup Hwang are first, second, and corresponding author, respectively. Won-sup Hwang has designed research, Hee-ju Kim has performed research and analyzed the data, and Hee-ju Kim and Jong Wan Hu have written the paper. All authors have read and approved the final manuscript.

\section{Conflicts of Interest}

The authors declare no conflict of interest.

\section{References}

1. AISC. Steel Construction Manual, 14th ed.; American Institute of Steel Construction: Chicago, IL, USA, 2007.

2. KSCE Committee. Korean Highway Bridge Specifications; Ministry of Construction and Transportation: Seoul, Korea, 2008.

3. Kanvinde, A.M.; Jordan, S.J.; Cooke, R.J. Exposed column base plate connections in moment frames-Simulations and behavioral insights. J. Constr. Steel Res. 2013, 84, 82-93.

4. Lee, D.-Y.; Goel, S.C.; Stojadinovic, B. Exposed Column-Base Plate Connections Bending about Weak Axis: 1. Numerical Parametric Study. Int. J. Steel Struct. 2008, 8, 11-27.

5. Lee, D.-Y.; Goel, S.C.; Stojadinovic, B. Exposed Column-Base Plate Connections Bending About Weak Axis: 2. Experimental Study. Int. J. Steel Struct. 2008, 8, 29-41. 
6. Lee, S.-J.; Lu, L.W. Cyclic Test of Full Scale Composite Joint Sub-assemblages. J. Struct. Eng. 1989, 115, 1997-1998.

7. Astaneh, A.; Bergsma, G.; Shen, J.H. Behavior and Design of Base Plates for Gravity, Wind and Seismic Loads. In Proceeding of the AISC National Steel Construction Conference, Las Vegas, NV, USA, 3-5 June 1992.

8. Park, Y.-M.; Hwang, W.-S.; Yoon, T.-Y.; Hwang, M.-O. A new Base Plate System using Deformed Reinforcing Bars for Concrete Filled Tubular Column. Steel Comp. Struct. 2005, 5, 375-394.

9. Chung, J.; Matsui, C. SRC Standards in Japan and Comparison of Various Standards for CFT Columns. Int. J. Steel Struct. 2005, 5, 315-323.

10. Hognestad, E.; Hanson, N.W.; McHenry, D. Concrete Stress Distribution in Ultimate Stress Design. ACI J. 1955, 27, 455-479.

11. Park, K.-D.; Kim, H.-J.; Hwang, W.-S. Experimental and Numerical Studies on the Confined Effect of Steel Composite Circular Columns Subjected to Axial Load. Int. J. Steel Struct. 2012, 12, 253-265.

12. Marson, J.; Bruneau, M. Cyclic Testing of Concrete-Filled Circular Steel Bridge Piers having Encased Fixed-Based Detail. J. Bridge Eng. 2004, 9, 14-23.

(C) 2015 by the authors; licensee MDPI, Basel, Switzerland. This article is an open access article distributed under the terms and conditions of the Creative Commons Attribution license (http://creativecommons.org/licenses/by/4.0/). 